\title{
Synoptic Weather Patterns and Associated Air Pollution in Taiwan
}

\author{
Chia-Hua Hsu, Fang-Yi Cheng* \\ Department of Atmospheric Sciences, National Central University, Taoyuan 32001, Taiwan
}

\begin{abstract}
In this study, cluster analysis is applied to the daily averaged wind fields and sea-level pressure observed at surface weather stations in Taiwan from January 2013 to March 2018 to classify the synoptic weather patterns and study the characteristics of corresponding air pollutants, including fine particulate matter $\left(\mathrm{PM}_{2.5}\right)$, coarse particulate matter $\left(\mathrm{PM} \mathrm{M}_{10}\right)$, and ozone $\left(\mathrm{O}_{3}\right)$. The classification identified six weather types: Clusters 1, 2, and $3(\mathrm{C} 1-\mathrm{C} 3)$, which are typical winter weather types and associated with high air pollutant concentrations - $\mathrm{C} 3$, in particular, influenced by weak synoptic weather, is associated with the lowest wind speeds and the highest $\mathrm{PM}_{2.5}$ and $\mathrm{PM}_{10}$ concentrations and represents the most prevalent weather type that is prone to the occurrence of $\mathrm{PM}_{2.5}$ events; $\mathrm{C} 4$, which occurs mostly during seasonal transition months and is associated with the highest $\mathrm{O}_{3}$ concentrations; and $\mathrm{C} 5$ and $\mathrm{C} 6$, which are summer weather types with low air pollutant concentrations.

Further analysis of the local wind flow using the $0.3^{\circ}$ ERA5 reanalysis dataset and surface-observed wind data indicates that in western Taiwan, the land-sea breeze is embedded within the synoptic weather type of C3, which is favorable to air pollutant accumulation. However, when the prevailing northeasterly wind is obstructed by the Central Mountain Range, southwestern Taiwan, being situated on the leeside of the mountains, often exhibits the worst air pollution due to stagnant wind conditions.
\end{abstract}

Keywords: Synoptic weather classification; Cluster analysis; $\mathrm{PM}_{2.5}$; Ozone; Stagnant wind.

\section{INTRODUCTION}

Air pollution is an important environmental issue in Taiwan and can be either locally produced or transported long distances from East Asia (Cheng et al., 2012; Chuang et al., 2017). The major domestic anthropogenic emissions are from urban areas, coal-fired power plants, crude oil refinery plants, industrial parks, and major highways and are emitted mostly in western Taiwan (Fang and Chen, 1996; Hsu and Cheng, 2016). In addition to emissions, meteorological conditions have been shown to play an important role in affecting air pollution dispersion in Taiwan (Tsai et al., 2008, 2011; Lai, 2014).

Identifying the synoptic weather patterns and large-scale circulation patterns represents a useful method of studying air pollution problems (Rainham et al., 2005; Cheng et al., 2013; Vanos et al., 2015; Hsu and Cheng, 2016). Calvo et al. (2010) characterized the chemical composition of rainwater based on the origin of air masses and found a strong relationship with the origin of air masses and precipitation.

\footnotetext{
${ }^{*}$ Corresponding author.

Tel.: +886-3-4227151-65508; Fax: +886-3-425-6841

E-mail address: bonniecheng18@gmail.com
}

The weather classification method can be subjective, such as manual categorizations of weather maps, and it can also be objective, such as the cluster analysis method, which is used to categorize data and has been applied in many studies for classifying weather patterns (Kidson, 2000; Coleman and Roger, 2007; Russo et al., 2015). Ngan and Byun (2011) applied the two-stage cluster analysis method to classify the synoptic weather patterns over eastern Texas using the $850 \mathrm{hPa}$ wind fields for the 5-month ozone $\left(\mathrm{O}_{3}\right)$ season (May-September) in the years 2005 and 2006. The results demonstrate the effectiveness of using wind fields for classifying the weather pattern and clearly identified the associated $\mathrm{O}_{3}$ characteristics among the different clusters.

Taiwan is an island located on the southeastern fringe of East Asia. The synoptic weather conditions are dominated by the western North Pacific subtropical high-pressure system during summer and the Asian continental anticyclone during winter and spring and further complicated by the land-ocean distribution and high Central Mountain Range (CMR), which runs from north to south across the island. This study was conducted to develop synoptic weather classifications in Taiwan using the cluster analysis method and investigate the role of meteorological conditions in air pollutant concentrations, including fine particulate matter $\left(\mathrm{PM}_{2.5}\right)$, coarse particulate matter $\left(\mathrm{PM}_{10}\right)$ and $\mathrm{O}_{3}$. The objectives of this study are as follows: (1) Study the characteristics of 
synoptic weather patterns and their associated circulation patterns in Taiwan; and (2) examine the role of synoptic weather patterns on $\mathrm{PM}_{2.5}, \mathrm{PM}_{10}$, and $\mathrm{O}_{3}$ concentrations in different areas of western Taiwan.

\section{METHODOLOGY AND DATA}

Cluster analysis is an objective classification method that establishes relatively uniform groups from the input data, and it separates data into distinctive clusters by minimizing variance within each group and maximizing variance between groups. In this study, a two-stage clustering method was applied to produce the weather classifications in Taiwan. In the first step, the initial number of clusters and the centroids of the clusters were determined and used as seeds in the second stage for the initiation of the k-means cluster analysis (MacQueen, 1967). The hourly wind speed and wind direction and the sea level pressure (SLP) observed at Central Weather Bureau (CWB) surface stations in Taiwan (refer to Fig. 1 for station location) are used for the cluster analysis. The hourly observed wind data are first decomposed into $\mathrm{U}$ and $\mathrm{V}$ components, and daily averaged values are estimated. The wind field is selected for the cluster analysis because it provides information on the air pollution dispersion and transport behavior. Moreover, the cluster analysis experiments are applied by including and excluding the SLP variable. The results indicate that the inclusion of the SLP in the cluster analysis can enhance the distinction between the summer and winter classified weather types; therefore, it is included for weather classification in this study.

The study period is from January 2013 to March 2018.
To avoid discussions on the tropical depression and typhoon related weather types, the two-stage cluster analysis was applied twice. The first application of the cluster analysis identified a cluster that is associated with the tropical depression and typhoon system (due to the inclusion of the SLP) and includes 35 days (refer to Supplementary Information).

We excluded the 35 days that are affected by typhoons and re-apply the cluster analysis. Moreover, before applying the cluster analysis, the variables are normalized by calculating the standard score of each observed variable based on Formula (1):

$$
\mathrm{Z}=\frac{X-\mu}{\sigma}
$$

where $Z$ is the standard score of meteorological variable; $X$ is the observed surface U, V, and SLP; and $\mu$ and $\sigma$ denote the mean and standard deviation of each meteorological field.

The number of classified clusters is determined according to the silhouette value that measures the similarity within the cluster and the dissimilarity between clusters (Rousseeuw, 1987). In this study, the variation of the silhouette value becomes small when the number of clusters is greater than six; therefore, six clusters are set as the final classified results. For each identified cluster, the mean values of temperature, precipitation, and wind speed, and $\mathrm{PM}_{2.5}$, $\mathrm{PM}_{10}$, and $\mathrm{O}_{3}$ concentrations acquired from the Taiwan Environmental Protection Agency (EPA) air quality monitoring stations (refer to Fig. 1 for station location) are

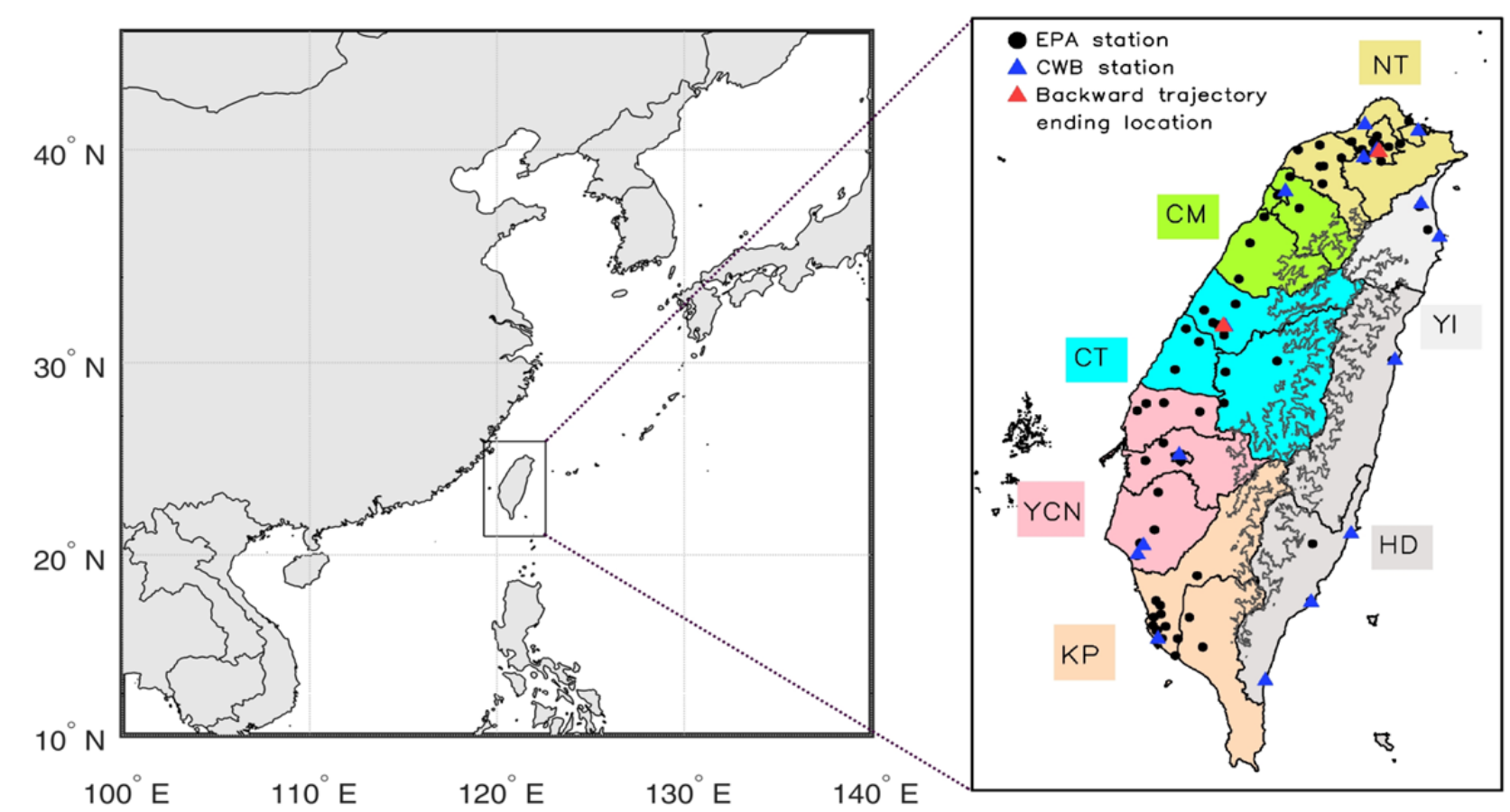

Fig. 1. Black points identify the locations of EPA surface stations. Blue triangles identify the locations of CWB surface stations. Red triangles identify the forty-eight-hour backward trajectory ending points. The seven AQZs (NT, CM, CT, YCN, KP, YI, and HD) are identified by name. The contour line indicates the mountain range (CMR). 
analyzed. The daily mean SLP and horizontal wind field data from the ERA5 reanalysis data (Hersbach and Dee, 2016) were used to produce the composite surface weather map for each cluster.

Due to the complicated geographical location and topographical conditions in Taiwan, the meteorological conditions can change distinctively from the northern to southern parts of Taiwan. Based on distinct characteristics of the meteorological and emission conditions, the Taiwan EPA has divided the nation into seven air quality zones (AQZs), namely, northern Taiwan (NT), the Chu-Miao area $(\mathrm{CM})$, central Taiwan (CT), the Yun-Chia-Nan area (YCN), the Kao-Ping area (KP), the Hua-Dong area (HD), and Yilan (YI). The analysis and discussion consider five AQZs (NT, CM, CT, YCN, and KP) (Fig. 1) to examine the air pollution problem in different areas of western Taiwan. The HD and YI areas located in eastern Taiwan are not discussed due to the lower impact of local anthropogenic emissions (TEDS-9.0, 2016).

\section{RESULTS AND DISCUSSION}

\section{Characterization of the Six Weather Patterns}

Based on the cluster analysis results, six weather patterns are identified. Table 1 summarizes the number of days; number of $\mathrm{PM}_{2.5}$ event days; daily mean $\mathrm{PM}_{2.5}, \mathrm{PM}_{10}$, and $\mathrm{O}_{3}$ concentrations and wind speed; and daily accumulated precipitation averaged over Taiwan for each cluster during

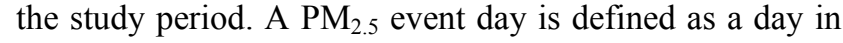
which there are more than 30 air quality monitoring stations located in western Taiwan with daily mean $\mathrm{PM}_{2.5}$ concentrations exceeding $35 \mathrm{\mu g} \mathrm{m}^{-3}$ (the $24-\mathrm{h} \mathrm{PM}_{2.5}$ standard in Taiwan). A total of 67 stations are located in western Taiwan, and 30 stations represent approximately half of the total number of stations located in western Taiwan. Overall, the occurrence of days in each cluster is relatively uniform, with no exceedingly small or large clusters observed, and the classification results can represent the general weather patterns in Taiwan.

Fig. 2 shows the composite map of the mean SLP and surface wind fields for each weather type. Fig. 3 shows the number of days and $\mathrm{PM}_{2.5}$ event days that occurred in each month for each cluster during the study period.

For Cluster $1(\mathrm{C} 1)$, Taiwan is affected by northeasterly monsoonal (NEM) flow due to the intrusion of the Asian continental anticyclone system. C1 occurs for 251 days (13.1\%) and appears mostly from November to March during the winter months. Among the six clusters, the mean wind speed is the highest $\left(2.35 \mathrm{~m} \mathrm{~s}^{-1}\right)$ in the $\mathrm{C} 1$ cluster due to the prevalence of the NEM flow. Although the strong wind fields can disperse the air pollutants, the mean $\mathrm{PM}_{2.5}\left(28.35 \mu \mathrm{g} \mathrm{m}{ }^{-3}\right)$ and $\mathrm{PM}_{10}\left(60.19 \mu \mathrm{g} \mathrm{m} \mathrm{m}^{-3}\right)$ concentrations are the third highest among the six clusters. Due to the influence of the NEM flow, air pollution can be contributed by long-range transported (LRT) air pollutants from East Asia.

Cluster 2 (C2) occurs following the $\mathrm{C} 1$ weather type that moves to the east coast of China. With the eastward movement of the anticyclone, the prevailing wind in Taiwan is affected by weak northeasterly to easterly flows due to continental high-pressure peripheral circulation. The monthly occurrence is similar to that of $\mathrm{C} 1$, and it mostly appears in the cold season from November to March, although the number of occurrences is 342 days (17.85\%), which is higher than the number of $\mathrm{Cl}$ occurrences (Fig. 3). Both $\mathrm{C} 1$ and $\mathrm{C} 2$ are typical winter weather types. The averaged $\mathrm{PM}_{2.5}$ and $\mathrm{PM}_{10}$ concentrations in the $\mathrm{C} 2$ cluster are the second highest among the clusters.

Cluster 3 (C3) occurs after the eastward passage of the $\mathrm{C} 2$ weather type. When the continental anticyclone is located farther from the Asian continent, Taiwan is under the influence of weak synoptic weather and affected by the weak easterly to southeasterly flow. Due to the weak synoptic easterly wind, western Taiwan often exhibits stagnant wind conditions and strong subsidence behavior due to the terrain blocking by the CMR (Hsu and Cheng, 2016). C3 is associated with the lowest wind speed $\left(1.3 \mathrm{~m} \mathrm{~s}^{-1}\right)$ and the highest $\mathrm{PM}_{2.5}\left(35.35 \mu \mathrm{g} \mathrm{m}^{-3}\right)$ and $\mathrm{PM}_{10}\left(65.48 \mu \mathrm{g} \mathrm{m}^{-3}\right)$ concentrations. C3 typically occurs from October until April, with the highest occurrence frequency appearing in March. The number of $\mathrm{PM}_{2.5}$ event days (160 days) is also the highest in the $\mathrm{C} 3$ cluster.

C4 mostly occurs in April and May when the winter season is in transition to the summer season and September and October when the summer season is in transition to the winter season. $\mathrm{PM}_{2.5}$ event days also occur in the seasonal transition months but are less frequent than in the $\mathrm{C} 1, \mathrm{C} 2$, and C3 weather types. The surface weather map indicates a weak anticyclone over the Asian continent; in addition, the Pacific subtropical high-pressure system does not have an apparent influence in Taiwan. The precipitation observed in the C4 cluster is mainly from the Meiyu frontal system, which typically occurs in May and June. Notably, C4 is associated with the highest mean $\mathrm{O}_{3}$ concentration

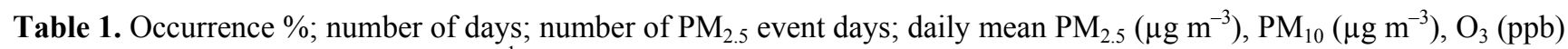
concentrations; wind speed (WS) $\left(\mathrm{m} \mathrm{s}^{-1}\right)$; and daily accumulated precipitation $(\mathrm{mm})$ averaged over Taiwan for each cluster.

\begin{tabular}{lllllllll}
\hline cluster & $\begin{array}{l}\text { occurrence } \\
\%\end{array}$ & $\begin{array}{l}\text { number of } \\
\text { days }\end{array}$ & $\begin{array}{l}\text { number of } \mathrm{PM}_{2.5} \\
\text { event days }\end{array}$ & $\mathrm{PM}_{2.5}$ & $\mathrm{PM}_{10}$ & $\mathrm{O}_{3}$ & WS & Rain \\
\hline C1 & 13.1 & 251 & 50 & 28.35 & 60.19 & 31.45 & 2.35 & 3.02 \\
$\mathrm{C} 2$ & 17.85 & 342 & 89 & 30.31 & 60.86 & 31.91 & 1.87 & 1.55 \\
$\mathrm{C} 3$ & 17.01 & 326 & 160 & 35.35 & 65.48 & 30.79 & 1.30 & 1.80 \\
C4 & 17.07 & 327 & 40 & 23.85 & 48.47 & 34.13 & 1.82 & 4.53 \\
C5 & 15.14 & 290 & 14 & 17.02 & 36.41 & 22.55 & 1.66 & 9.88 \\
C6 & 18.01 & 345 & 10 & 17.69 & 36.63 & 24.10 & 1.74 & 7.25 \\
\hline
\end{tabular}




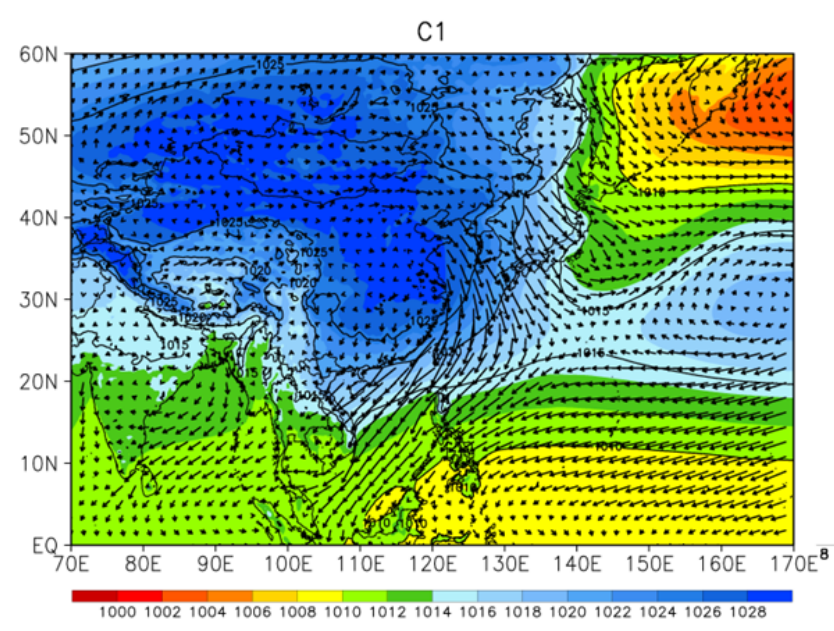

$\mathrm{C} 2$

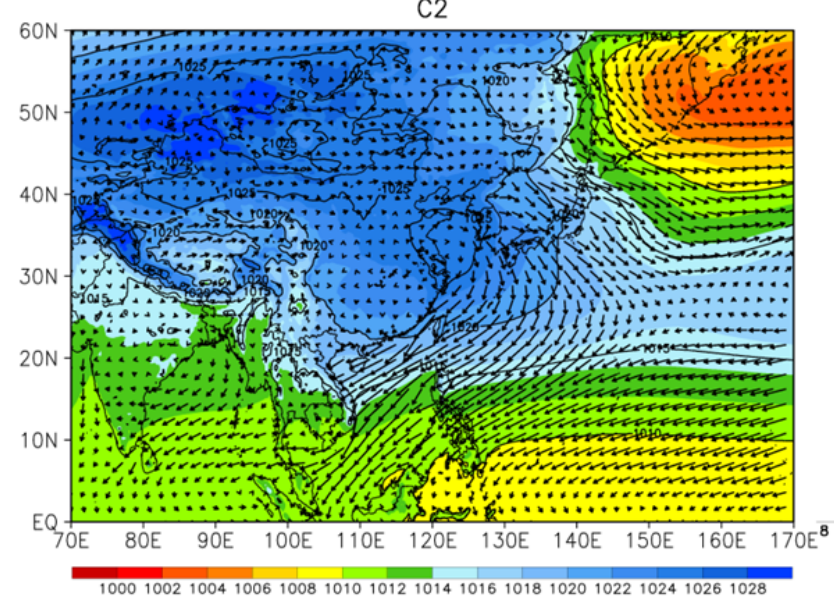

C3

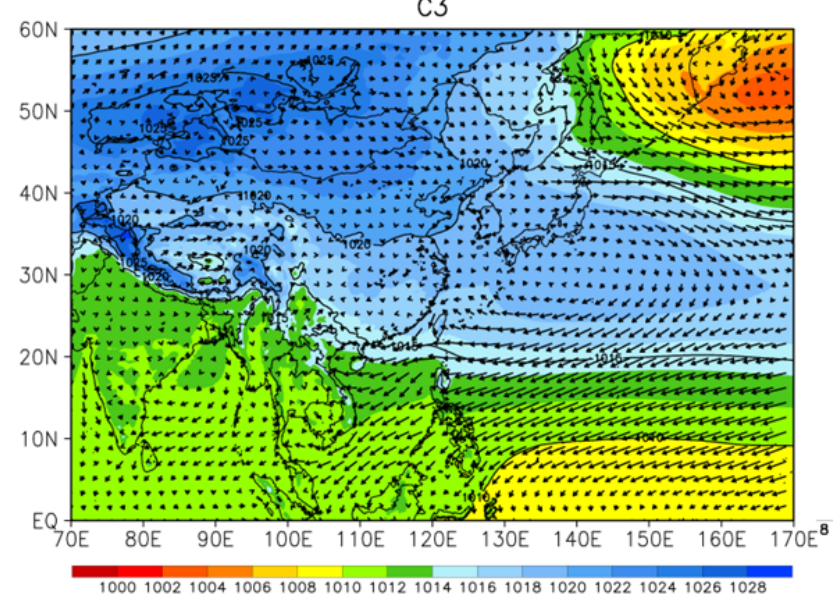

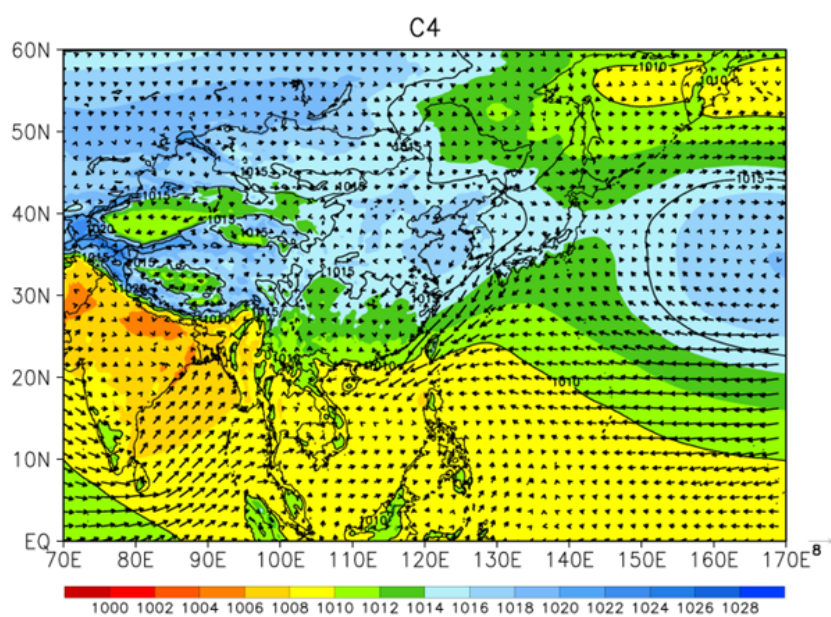

C5

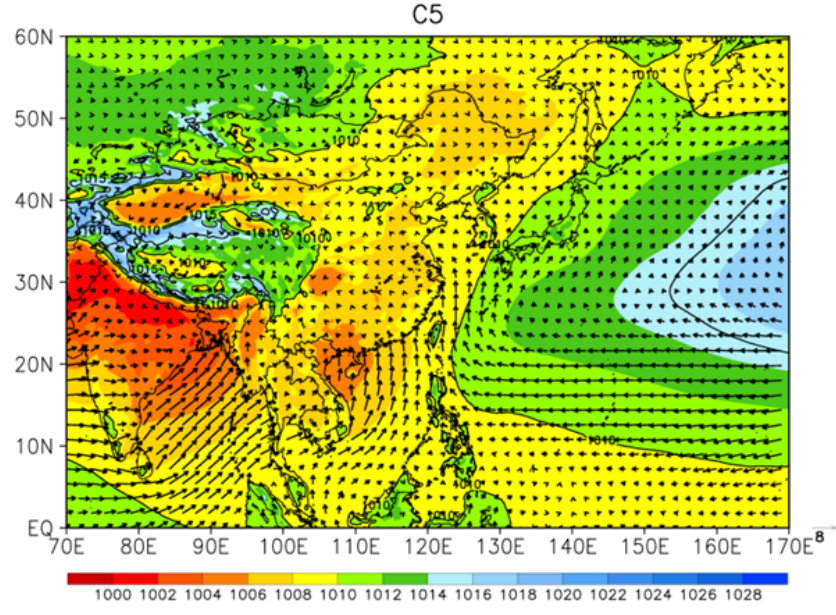

C6

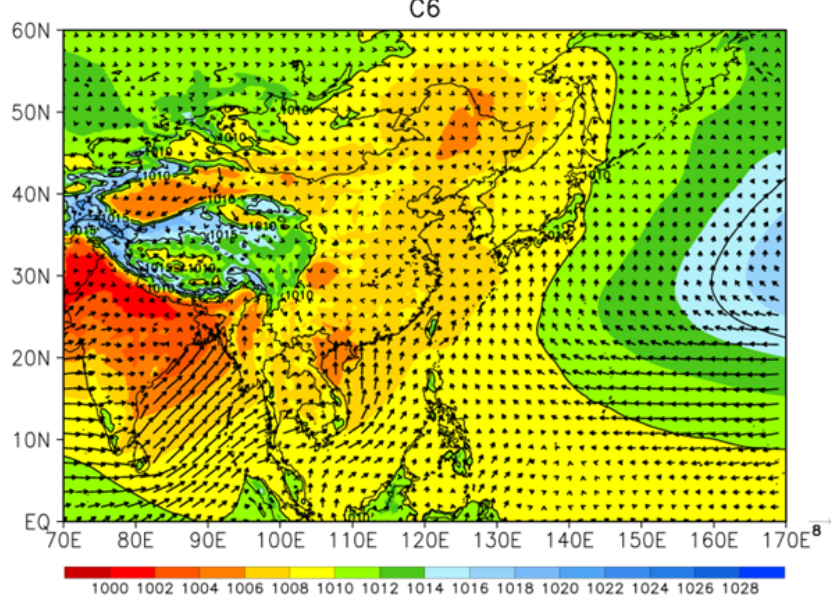

Fig. 2. Composite plot of SLP (hPa; shaded colors) and surface wind vectors $\left(\mathrm{m} \mathrm{s}^{-1}\right)$ for the $\mathrm{C} 1-\mathrm{C} 6$ clusters.

(34.13 ppb) among the six clusters (Table 1). In Taiwan, during the summer season, although the photochemical reaction is strong, low concentrations of $\mathrm{O}_{3}$ are observed due to the enhanced vertical dispersion (Tsai et al., 2008) and the plentiful precipitation that is induced by afternoon thunderstorms and mesoscale convective systems (Yen and Chen, 2000). The analysis of the $\mathrm{O}_{3}$ variation shows that the monthly $\mathrm{O}_{3}$ concentration is relatively higher during the seasonal transition months such as October and April (refer to Supplementary Information). During the seasonal transition months, when the photochemical reaction is still strong compared to that of the winter months together with the reduced ventilation capability, the $\mathrm{O}_{3}$ concentration can accumulate. The average temperature is also higher in $\mathrm{C} 4$ than $\mathrm{C} 1-\mathrm{C} 3$ (Fig. 3). As a result, the $\mathrm{C} 4$ weather type exhibits the highest mean $\mathrm{O}_{3}$ concentration.

In Cluster 5 (C5), due to the westward stretching of the Pacific subtropical high-pressure system, the prevailing wind in Taiwan is associated with a weak southeasterly to southerly flow. C5 mainly appears in the warm season from 
C1 $(n=251,13.1 \%)$

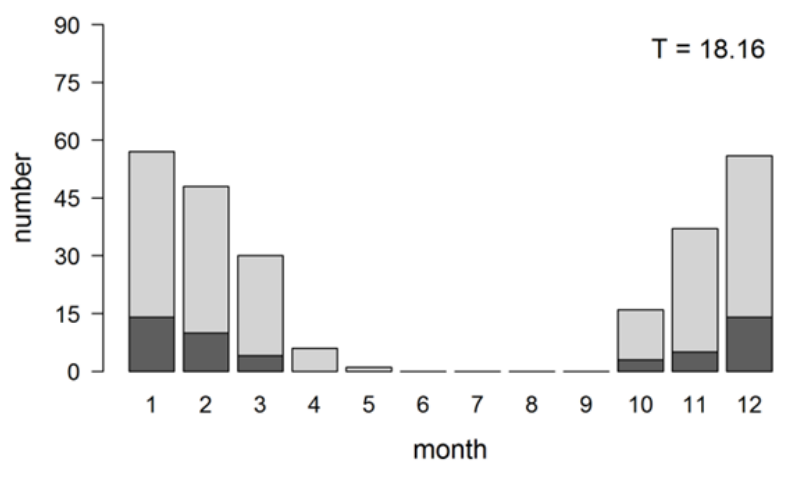

C2 $(n=342,17.85 \%)$

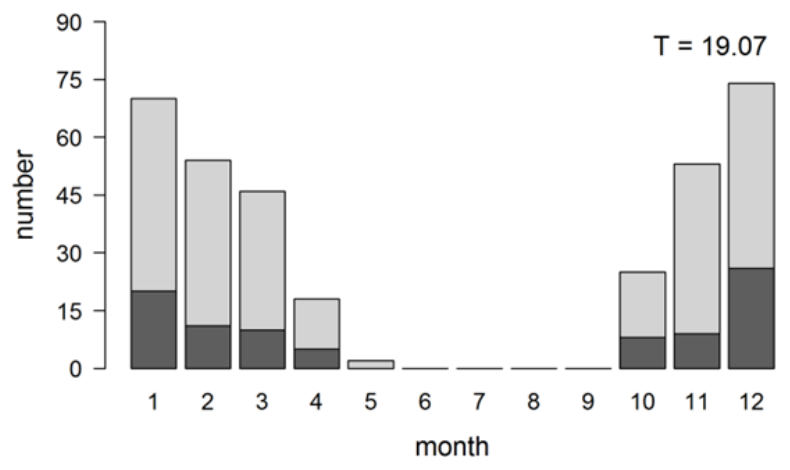

C3 $(n=326,17.01 \%)$

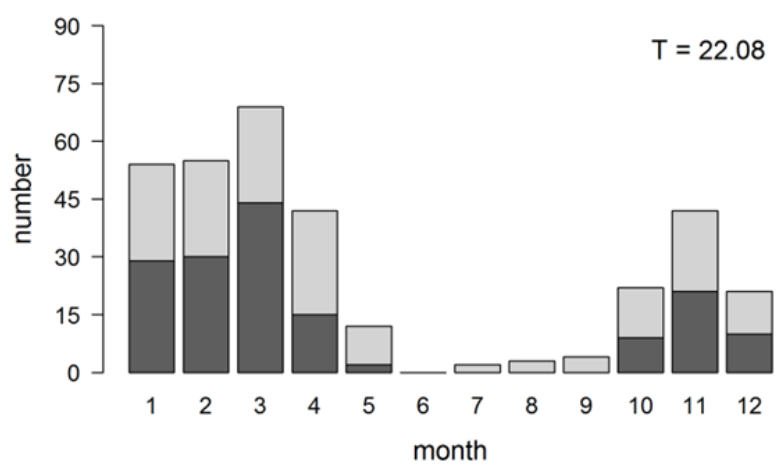

C4 $(n=327,17.07 \%)$

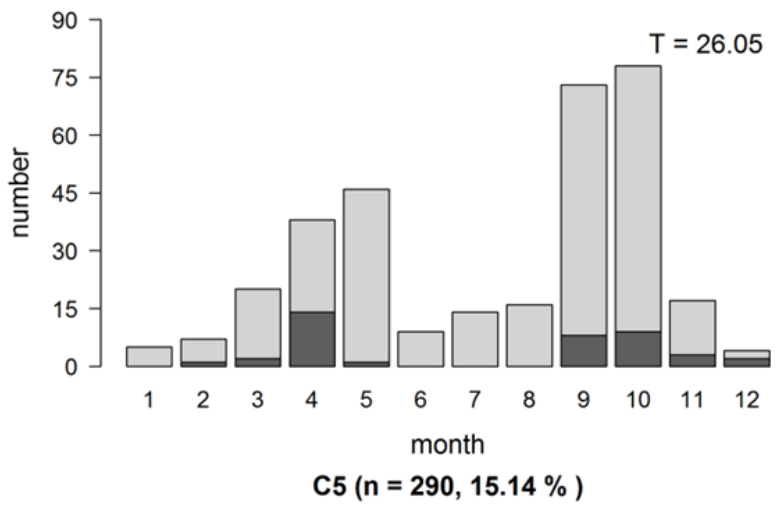

$\mathrm{T}=28.05$

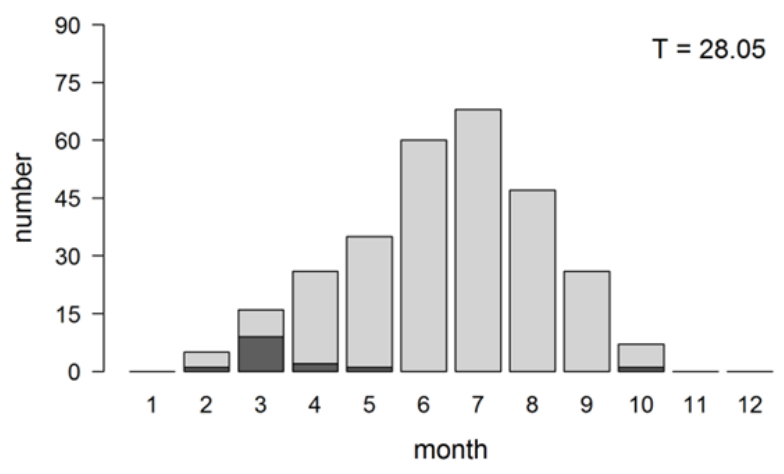

C6 $(n=345,18.01 \%)$

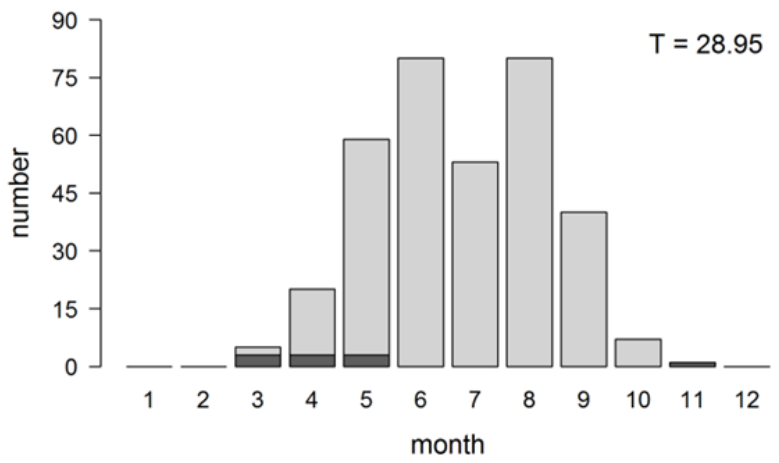

Fig. 3. The light gray and dark gray colors represent the number of occurrences and $\mathrm{PM}_{2.5}$ event days individually in each month for the $\mathrm{C} 1-\mathrm{C} 6$ clusters. The upper-right corner shows the temperature $\left({ }^{\circ} \mathrm{C}\right)$ averaged from all the air quality surface stations.

late spring to early autumn, occurs for 290 days (15.14\%), and is associated with the highest rainfall among the six clusters. In Cluster 6 (C6), with weaker influence of the subtropical high-pressure system compared to C5, the prevailing wind is southwesterly. C6 occurs for 345 days (18.01\%), mainly from May to August. Both C5 and C6 are summer weather types and associated with higher rainfall and lower air pollutant concentrations than the other clusters. A comparison between the $\mathrm{C} 5$ and C6 clusters shows that the $\mathrm{PM}_{2.5}, \mathrm{PM}_{10}$, and $\mathrm{O}_{3}$ concentrations are all slightly higher in $\mathrm{C} 6$ than $\mathrm{C} 5$, which might be related to the higher rainfall in the $\mathrm{C} 5$ cluster.

\section{Backward Trajectory for C1-C4 Weather Types}

Forty-eight-hour backward trajectories (Fig. 4) were generated for the days within the top $20^{\text {th }}$ percentiles of
$\mathrm{PM}_{2.5}$ concentrations in the $\mathrm{C} 1-\mathrm{C} 4$ clusters using the HYSPLIT model (Stein et al., 2015). C5 and C6 are not discussed because they are less associated with air pollution problems. In general, northern Taiwan is more easily affected by the LRT air pollutants from East Asia; however, the emission contributions in the central to southern part of western Taiwan are mainly from the locally released emissions. To distinguish the influence of paths of the air masses, we selected two stations located in Taipei (northern Taiwan) and Taichung (central part of western Taiwan) as the trajectory ending points (refer to Fig. 1 for locations).

In the $\mathrm{C} 1$ cluster, the majority of the backward trajectories ending at the northern station (Fig. 4) are passing over the Beijing-Tianjin-Hebei (BTH) region and Yangtze River Delta (YRD) region, where severe haze 

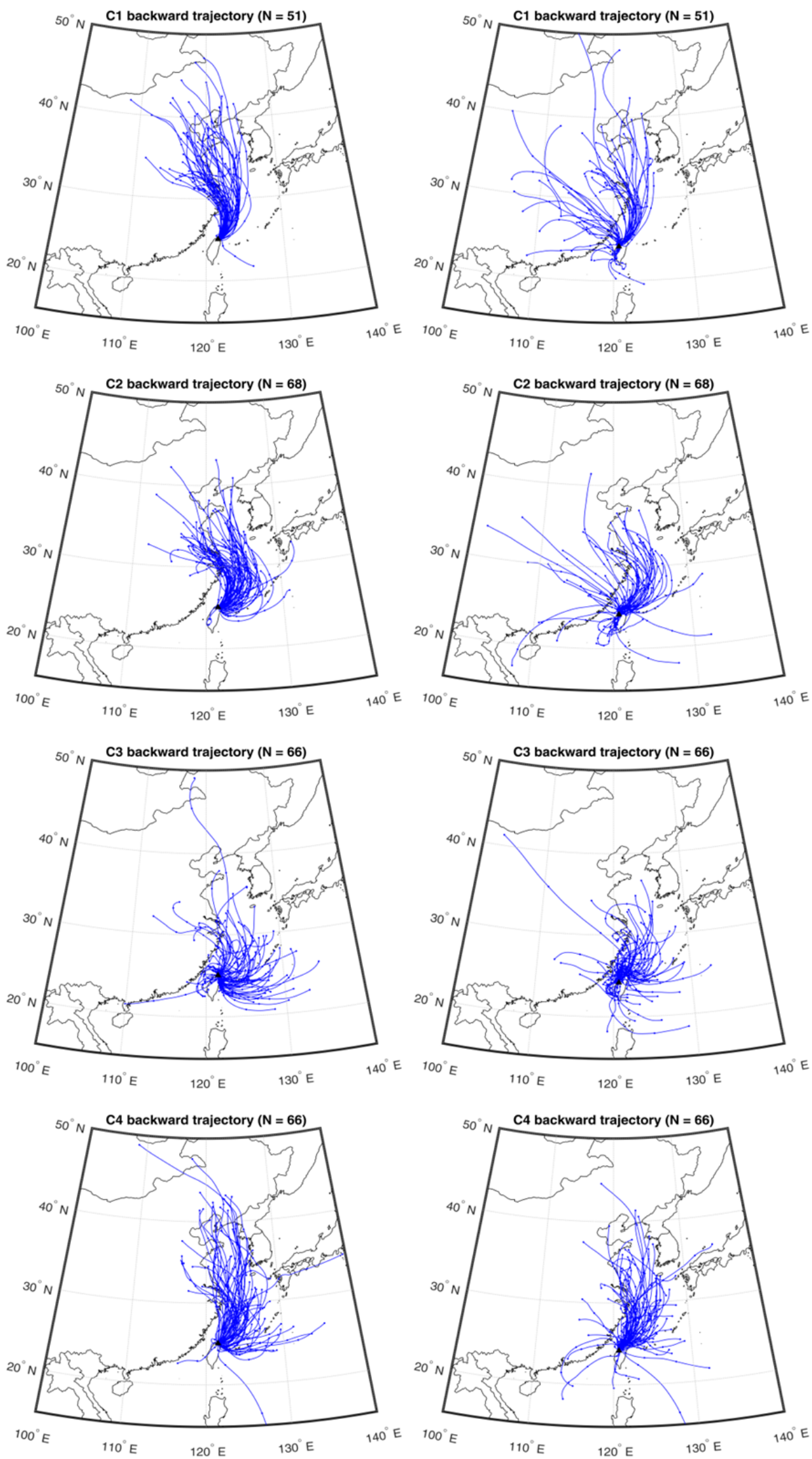

Fig. 4. Forty-eight-hour backward trajectories for the days within the top $20^{\text {th }}$ percentiles of $\mathrm{PM}_{2.5}$ concentrations for $\mathrm{C} 1-$ $\mathrm{C} 4$ clusters. $\mathrm{N}$ is the number of backward trajectories in each cluster. The left panel is for the ending location at the northern station. The right panel is for the ending location at the central station in western Taiwan. 
problems frequently occur (Cai et al., 2018). The backward trajectories ending at the central station can be from the northern China plains and southern China. The trajectories from the northern China plains can be associated with stronger NEM flows that can penetrate toward the southern region of Taiwan, while the trajectories from southern China can be associated with the weaker NEM flow and the air mass from southern China, which migrates eastward to the Taiwan area.

In the $\mathrm{C} 2$ cluster, for the backward trajectories ending at the northern station, some are from the YRD region, and some pass through the East China Sea, which indicates that northern Taiwan can be affected by LRT air pollutants. On the other hand, the backward trajectories ending at the central station are from the East China Sea and southern China, which indicates less impact of LRT air pollutants from heavily polluted regions in China such as BTH and YRD region.

In the $\mathrm{C} 3$ cluster, the backward trajectories ending at the northern station are mostly from the eastern ocean side of Taiwan while the backward trajectories ending at the central station are condensed in the surrounding areas, which indicates that the air pollution problem in the $\mathrm{C} 3$ cluster is mainly due to the local release of emissions.

In the $\mathrm{C} 4$ cluster, the majority of the backward trajectories are from the northern side. However, unlike the C1 cluster, they do not pass through the heavily polluted areas; rather, most of the trajectories pass through the East China Sea.

In general, the trajectory analysis indicated that northern Taiwan can have a significant influence from the LRT air pollutants from China in the $\mathrm{C} 1$ cluster. In the $\mathrm{C} 2$ cluster, the contribution of emission sources can have a mixed composition. Northern Taiwan can receive LRT air pollutants and locally released emissions; however, central Taiwan is mainly affected by locally released emissions. In the $\mathrm{C} 3$ cluster, air pollution is primarily caused by locally released emissions. In the $\mathrm{C} 4$ cluster, although most trajectories are from the northern side, they do not pass through the heavily polluted areas.

\section{Diurnal Variation of the Wind Fields and Air Pollutants in Each Cluster}

Fig. 5 shows the diurnal variations of the observed wind speed, wind direction, and $\mathrm{PM}_{2.5}, \mathrm{PM}_{10}$ and $\mathrm{O}_{3}$ concentrations averaged from the surface stations for the days in each cluster. The wind speed is highest in the $\mathrm{C} 1$ cluster and lowest in the $\mathrm{C} 3$ cluster. $\mathrm{C} 1, \mathrm{C} 2$, and $\mathrm{C} 4$ exhibit a northeasterly wind throughout the day. In the $\mathrm{C} 3$ cluster, an apparent land-sea breeze flow occurs with an onshore northwesterly wind formed during the day and offshore easterly wind during the night. C5 is affected by a southeasterly wind during the night and a southwesterly wind formed during the day. C6 presents a southerly wind during the night and southwesterly to westerly wind during the day.

For the $\mathrm{PM}_{2.5}$ concentrations, the maximum occurs between 10:00 or 11:00 local standard time (LST) in the C2-C6 clusters; however, the $\mathrm{C} 1$ cluster exhibits a different diurnal variation that can be attributed to LRT air pollutants.

During the winter season, the reduced rainfall results in a significant increase of the exposed riverbed area (Kuo et al., 2010). With a strong NEM flow, the fugitive dust emissions can be blown up from the bare land and deteriorate the air quality. Although the mean $\mathrm{PM}_{10}$ concentration is the highest in the $\mathrm{C} 3$ cluster due to the lowest wind speed, in the $\mathrm{C} 1$ cluster, there is an apparent $\mathrm{PM}_{10}$ peak appearing in the later afternoon that can be associated with the strong NEM flow and indicates the possible influence from riverbed dust emissions.

The $\mathrm{O}_{3}$ concentration shows a clear diurnal variation. The daily maximum occurs at 13:00 LST in the C1-C4 clusters; however, the daily maximum occurs one hour earlier at 12:00 LST in the C5-C6 clusters. In the C5 and C6 clusters, the formation of the cloud and the afternoon thunderstorm systems may limit photochemical reaction processes and reduce the $\mathrm{O}_{3}$ concentration. Additionally, Table 1 shows the maximum of the mean $\mathrm{O}_{3}$ concentration occurs in the $\mathrm{C} 4$ cluster; however, the daily maximum of the $\mathrm{O}_{3}$ concentrations occurs in the $\mathrm{C} 3$ cluster (Fig. 5). A comparison between the $\mathrm{C} 3$ and $\mathrm{C} 4$ clusters shows that the nighttime $\mathrm{O}_{3}$ concentration is generally lower in $\mathrm{C} 3$ than $\mathrm{C} 4$, which might be due to the stronger $\mathrm{O}_{3}$ titration reaction in the $\mathrm{C} 3$ cluster; as a result, the mean $\mathrm{O}_{3}$ concentration is higher in the $\mathrm{C} 4$ than the $\mathrm{C} 3$ cluster.

\section{Spatial Analysis of the Wind fields in Each Cluster}

The local air flow embedded within the synoptic weather can have a significant impact on air pollution dispersion. To further investigate the local air flow patterns, the ERA5 reanalysis dataset at a $0.3^{\circ}$ spatial resolution is used to conduct a wind analysis in the area of Taiwan. In addition, the behavior of the observed surface wind from the air quality monitoring stations is discussed. Figs. 6 and 7 show the spatial distribution of surface wind from the ERA5 reanalysis dataset layered with the observed surface wind fields at 02:00 and 14:00 LST, respectively, when the local land-sea breeze is likely to develop in western Taiwan. The analysis is excluded for C5 and C6 clusters due to the reduced issues with air pollution. The NEM flow affects the coastal areas of western Taiwan, and the impact is the strongest in the $\mathrm{C} 1$ cluster, followed by the $\mathrm{C} 2$ and $\mathrm{C} 4$ clusters. C3 exhibits the weakest wind condition with the prevailing easterly wind from the eastern side of Taiwan. The observed surface wind indicates the formation of the onshore sea breeze flow embedded within the synoptic wind flow in western Taiwan at 14:00 LST in the $\mathrm{C} 3$ cluster. In $\mathrm{C} 2$ and $\mathrm{C} 4$ clusters, the observed surface winds also reveal the onshore flow forming from the central to southern parts of western Taiwan, where the influence of the NEM flow becomes weaker than that over northern Taiwan. In fact, the land-sea breeze flow has been reported to lead to air pollutant accumulation in western Taiwan (Cheng et al., 2012).

Moreover, under the influence of the NEM flow, southwestern Taiwan is located on the leeside of the mountain, where the wind field tends to be stagnant due to 

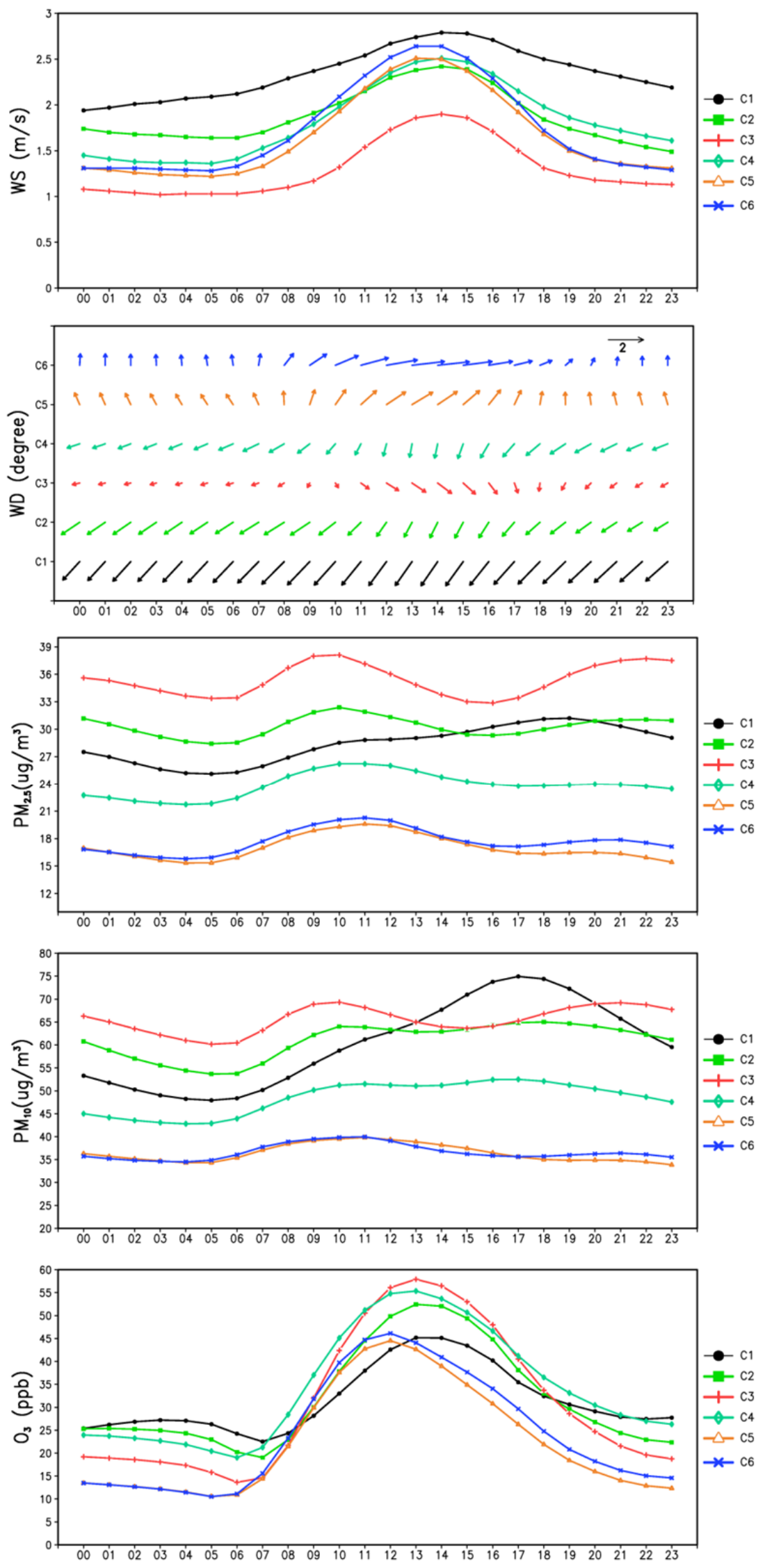

Fig. 5. Diurnal variation of the observed wind speed; wind direction; and $\mathrm{PM}_{2.5}, \mathrm{PM}_{10}$, and $\mathrm{O}_{3}$ concentrations averaged from the surface stations for the days in each cluster. 

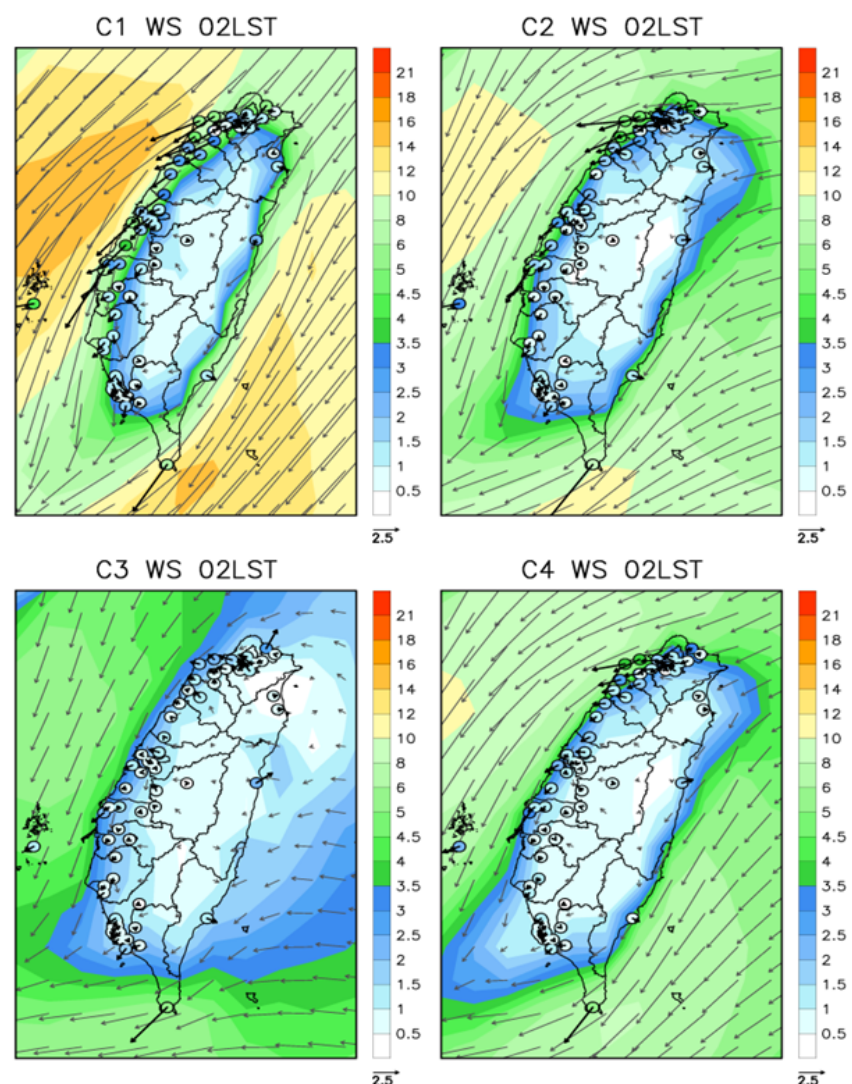

Fig. 6. Spatial distribution of surface wind $\left(\mathrm{m} \mathrm{s}^{-1}\right)$ from the ERA5 reanalysis dataset and observed surface wind ( $\left.\mathrm{s} \mathrm{s}^{-1}\right)$ from the EPA surface stations at 02:00 LST for the C1-C4 clusters.
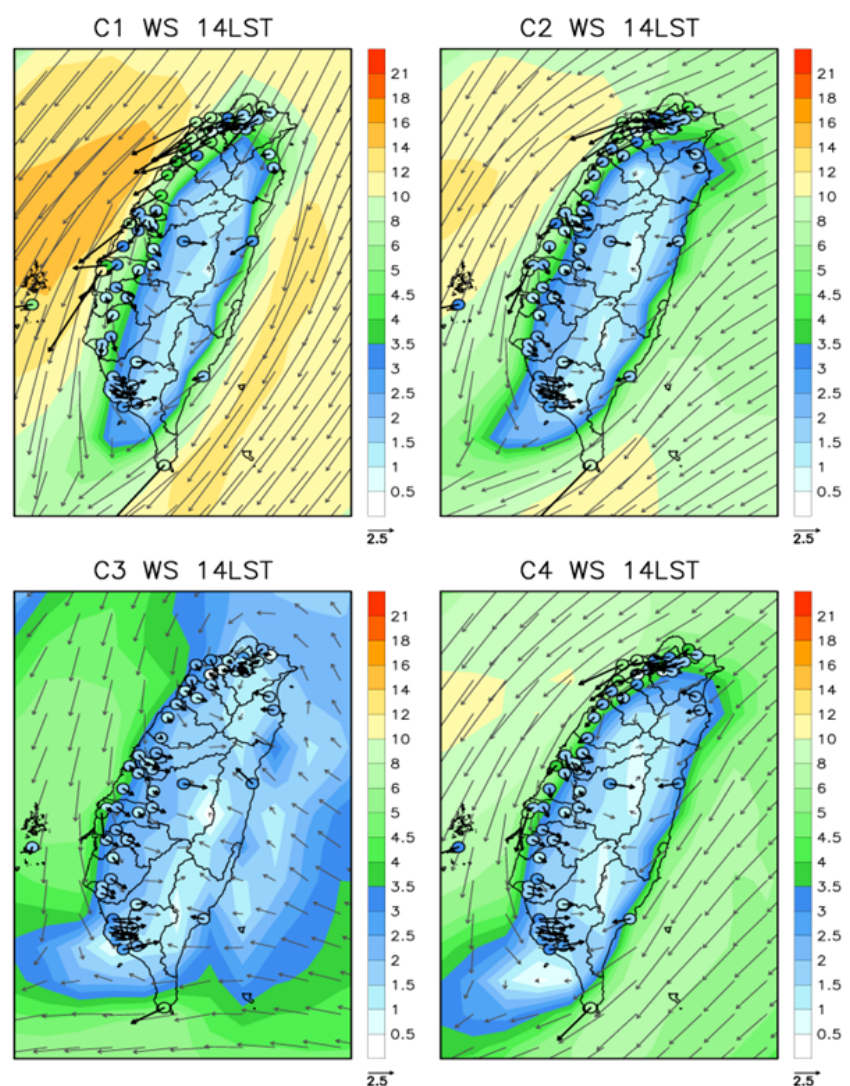

Fig. 7. Similar to Fig. 6 but at 14:00 LST. 
the terrain blocking by the CMR. The ERA5 reanalysis data shows a very weak wind field in the nearshore areas of southwestern Taiwan in the $\mathrm{C} 1-\mathrm{C} 4$ weather types.

\section{Characterization of the Air Pollutants in Each AQZ}

Fig. 8 presents a box plot that summarizes the mean wind speed; mean concentrations of $\mathrm{PM}_{2.5}, \mathrm{PM}_{10}$, and $\mathrm{O}_{3}$; and daily $\mathrm{O}_{3}$ maximum $\left(\mathrm{O}_{3 \max }\right.$, defined as the hourly maximum concentration observed during each day) in five AQZs for each cluster. The average is estimated based on the data from the air quality stations located within each AQZ. In terms of the wind speed, all five AQZs all exhibit very weak wind speeds in the $\mathrm{C} 3$ cluster. In the $\mathrm{C} 1-\mathrm{C} 4$ clusters, the KP area located in southwestern Taiwan always exhibits a weak wind field because it is situated on the leeside of the mountain, and a stagnant wind condition often forms

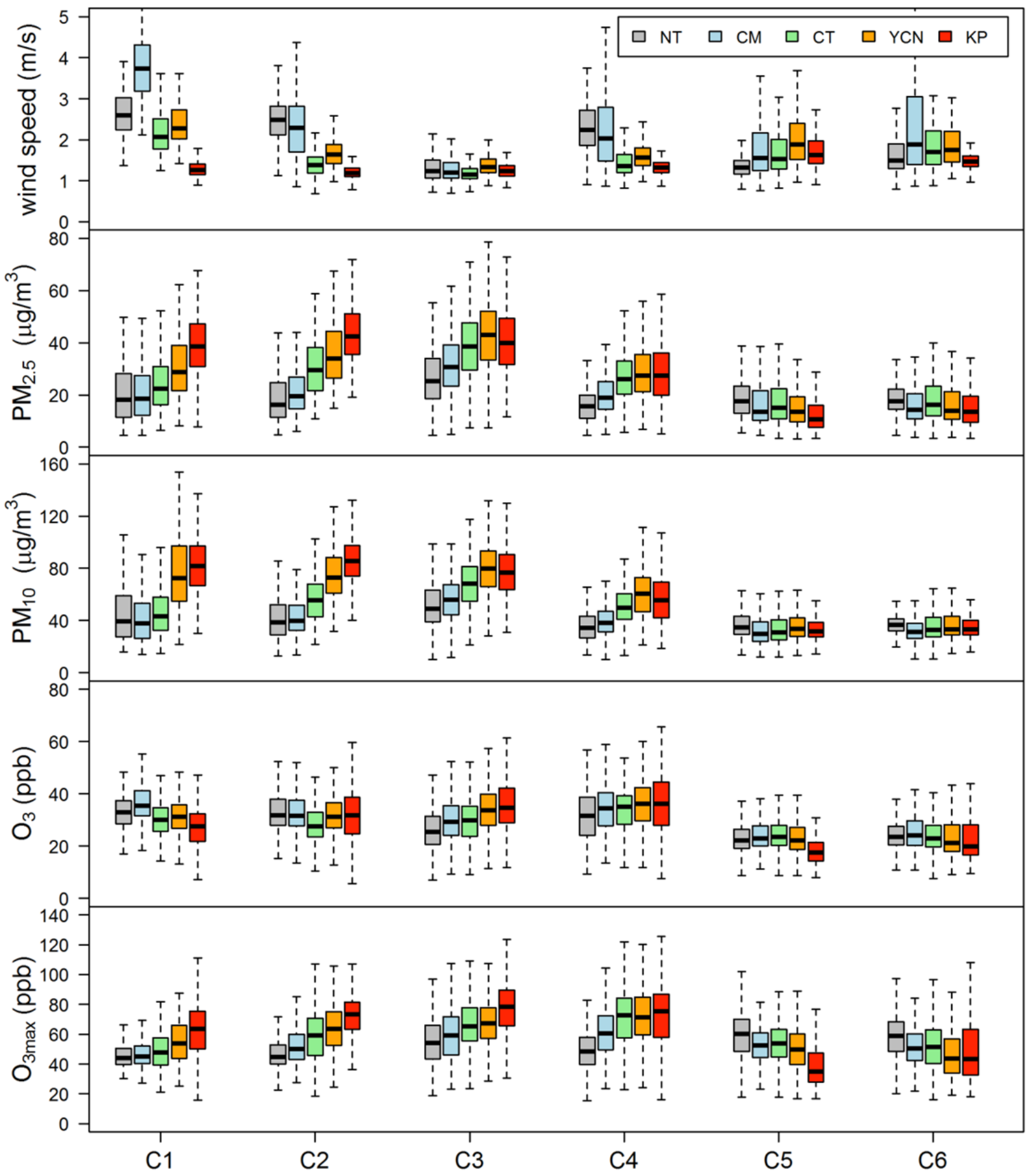

Fig. 8. From top to bottom: box plots of the mean wind speed; $\mathrm{PM}_{2.5}, \mathrm{PM}_{10}$, and $\mathrm{O}_{3}$ concentrations; and daily $\mathrm{O}_{3}$ maximum concentrations in five AQZs for C1-C6 clusters. The black bar is the median, and the upper and lower boundaries of the box denote the $75^{\text {th }}$ percentile $(\mathrm{Q} 3)$ and $25^{\text {th }}$ percentile $(\mathrm{Q} 1)$, respectively. The upper and lower whiskers show the interval between $\mathrm{Q} 3+1.5 \mathrm{IQR}$ and $\mathrm{Q} 1-1.5 \mathrm{IQR}$, where IQR is the interquartile range. 
under the influence of the NEM flow. The NT and CM areas exhibit relatively higher wind speeds in the $\mathrm{C} 1, \mathrm{C} 2$, and $\mathrm{C} 4$ clusters due to the influence of the NEM flow. In the $\mathrm{C} 2, \mathrm{C} 3$, and $\mathrm{C} 4$ clusters, the $\mathrm{CT}, \mathrm{YCN}$, and $\mathrm{KP}$ areas reveal a weaker wind speed compared with the NT and $\mathrm{CM}$ areas due to the terrain blocking by the CMR.

With the weak wind field, all five AQZs exhibit relatively higher $\mathrm{PM}_{2.5}$ concentrations in $\mathrm{C} 3$ than the other clusters, with the highest concentration occurring in the YCN area. The KP area generally exhibits higher $\mathrm{PM}_{2.5}$ concentrations compared to the other AQZs in the C1-C4 clusters due to the stagnant wind condition. Moreover, the prevailing NEM flow can bring the upstream air pollutants toward the KP area. In the $\mathrm{C} 1$ cluster, the $\mathrm{PM}_{2.5}$ and $\mathrm{PM}_{10}$ concentrations are higher in the NT area than the CM area, which can be attributed to the influence of transboundary air pollution from East Asia. The central to southern parts of western Taiwan (CT, YCN, and KP areas) are situated on the leeside of the mountains and often experience higher $\mathrm{PM}_{2.5}$ and $\mathrm{PM}_{10}$ concentrations than areas in northern Taiwan (NT and CM areas) in the $\mathrm{C} 1-\mathrm{C} 4$ weather types. $\mathrm{C} 5$ and $\mathrm{C6}$ are associated with lower $\mathrm{PM}_{2.5}$ and $\mathrm{PM}_{10}$ concentrations than the other clusters, with the lowest concentration occurring in the KP area. In general, the $\mathrm{PM}_{2.5}$ concentrations increase from south to north across Taiwan, and $\mathrm{PM}_{10}$ variations among the five AQZs are not significant in the $\mathrm{C} 5$ and $\mathrm{C} 6$ clusters.

The $\mathrm{PM}_{10}$ air pollution problem in Taiwan can be caused by river sand dust (Lin and Lin, 2012) and is more serious in the YCN and KP areas when under the influence of the strong NEM flow. $\mathrm{C} 1$ is associated with the strongest wind among the six clusters, and the YCN and KP areas exhibit higher $\mathrm{PM}_{10}$ concentrations because of river sand dust from the Zhuoshui River, which is located along the northern border of the YCN area (Kuo et al., 2010). However, the NT, CM, and CT areas exhibit low and even $\mathrm{PM}_{10}$ distributions in the $\mathrm{C} 1$ cluster.

Compared with the characteristics of $\mathrm{PM}_{2.5}$ and $\mathrm{PM}_{10}$, the mean $\mathrm{O}_{3}$ concentration in the $\mathrm{C} 1$ and $\mathrm{C} 2$ clusters is relatively higher in the NT and $\mathrm{CM}$ areas than the other AQZs, which can be attributed to the transboundary air pollutants from East Asia. In other words, when $\mathrm{C} 1$ and $\mathrm{C} 2$ weather types occur, the LRT $\mathrm{O}_{3}$ air pollutants can affect Taiwan due to the Asian continental outflow, and the effect is most significant in northern Taiwan (i.e., the NT and $\mathrm{CM}$ areas). However, $\mathrm{O}_{3 \max }$ exhibits the reverse pattern, with the highest concentration occurring in the KP area and lower concentrations occurring in the NT and CM areas. The impact of the transboundary $\mathrm{O}_{3}$ concentration is typically in the range of 40-60 ppb; however, the domestic emission contribution to the $\mathrm{O}_{3}$ concentration can exceed $90 \mathrm{ppb}$, which is more serious than LRT air pollutants (Cheng et al., 2012). The analysis of the $\mathrm{O}_{3 \max }$ concentration also reflects the importance of the locally released emissions, which contribute to the high $\mathrm{O}_{3}$ concentration more so than LRT air pollutants.

In the $\mathrm{C} 1-\mathrm{C} 4$ weather types, the highest $\mathrm{O}_{3 \max }$ concentrations appear in the KP area. In the $\mathrm{CT}, \mathrm{YCN}$, and $\mathrm{KP}$ areas, the $\mathrm{O}_{3 \max }$ concentration is higher in the $\mathrm{C} 4$ than the $\mathrm{C} 1-\mathrm{C} 3$ weather types. For the $\mathrm{C} 5$ and $\mathrm{C} 6$ clusters, the mean $\mathrm{O}_{3}$ concentrations are generally lower than that of the other clusters, and the $\mathrm{O}_{3 \max }$ concentration can reach a higher range in the NT area than the other AQZs.

Moreover, the spatial analysis targeting the $\mathrm{PM}_{2.5}$ concentration is conducted using the observed surface datasets. Fig. 9 shows the distributions of the daily mean $\mathrm{PM}_{2.5}$ concentrations and wind vector data observed from the EPA surface stations in Taiwan for all clusters. C3 shows an overall higher $\mathrm{PM}_{2.5}$ concentration compared with the other clusters, with particularly high concentrations occurring in the stations of the YCN area. The KP area tends to exhibit higher $\mathrm{PM}_{2.5}$ concentrations in the $\mathrm{C} 1-\mathrm{C} 3$ clusters, with the highest concentration appearing in the $\mathrm{C} 2$ cluster. The daily mean $\mathrm{PM}_{2.5}$ concentration is generally lower in the $\mathrm{C} 5$ and $\mathrm{C} 6$ clusters. In western Taiwan, the observed wind vectors clearly indicate that the NEM flow can reach into the southern region in the $\mathrm{C} 1$ cluster; however, the strength of the NEM flow weakens and is confined in the northern to central part in the $\mathrm{C} 2$ and $\mathrm{C} 4$ clusters.

\section{CONCLUSIONS}

To assess the effects of meteorological conditions on the concentrations of air pollutants, including $\mathrm{PM}_{2.5}, \mathrm{PM}_{10}$, and $\mathrm{O}_{3}$, in Taiwan, we applied cluster analysis in order to classify the synoptic weather patterns using the observed surface wind fields and SLP. Six weather patterns were identified: $\mathrm{C} 1$, which corresponds to the intrusion of the Asian continental anticyclone and is affected by the NEM flow; C2, which corresponds to the movement of the anticyclone eastward to the eastern coast of China and is affected by the continental high-pressure peripheral circulation; $\mathrm{C} 3$, which corresponds to a weak synoptic weather pattern and is affected by a weak easterly flow; $\mathrm{C} 4$, which corresponds to the weather pattern occurring during seasonal transition months and the presence of a weak NEM flow; C5, which corresponds to the westward stretching of the subtropical high-pressure system; and C6, which corresponds to the weather pattern associated with a southwesterly flow. C1, C2, and C3 are winter weather types and associated with higher air pollutant concentrations, C4 mostly appears in the seasonal transition months, and C5 and $\mathrm{C} 6$ are summer-related weather types and associated with low air pollutant concentrations.

Because the NEM flow prevails in C1, transboundary air pollutants from East Asia affect the air quality in Taiwan, and the impact is apparent in the NT and CM areas. Furthermore, the strong NEM flow also induces high $\mathrm{PM}_{10}$ loading in the YCN and KP areas due to Zhuoshui River sand dust. C3 exhibits the lowest wind speed, which is favorable to air pollutant accumulation and leads to the highest $\mathrm{PM}_{2.5}$ and $\mathrm{PM}_{10}$ concentrations, with the highest concentration appearing in the $\mathrm{YCN}$ area; this cluster is also the most prevalent weather type and prone to the occurrence of $\mathrm{PM}_{2.5}$ events. However, the mean $\mathrm{O}_{3}$ concentrations are higher in $\mathrm{C} 4$ than in $\mathrm{C} 1-\mathrm{C} 3$.

Among the five AQZs, the worst air pollution occurs in $\mathrm{KP}$, which tends to exhibit higher air pollutant concentrations 

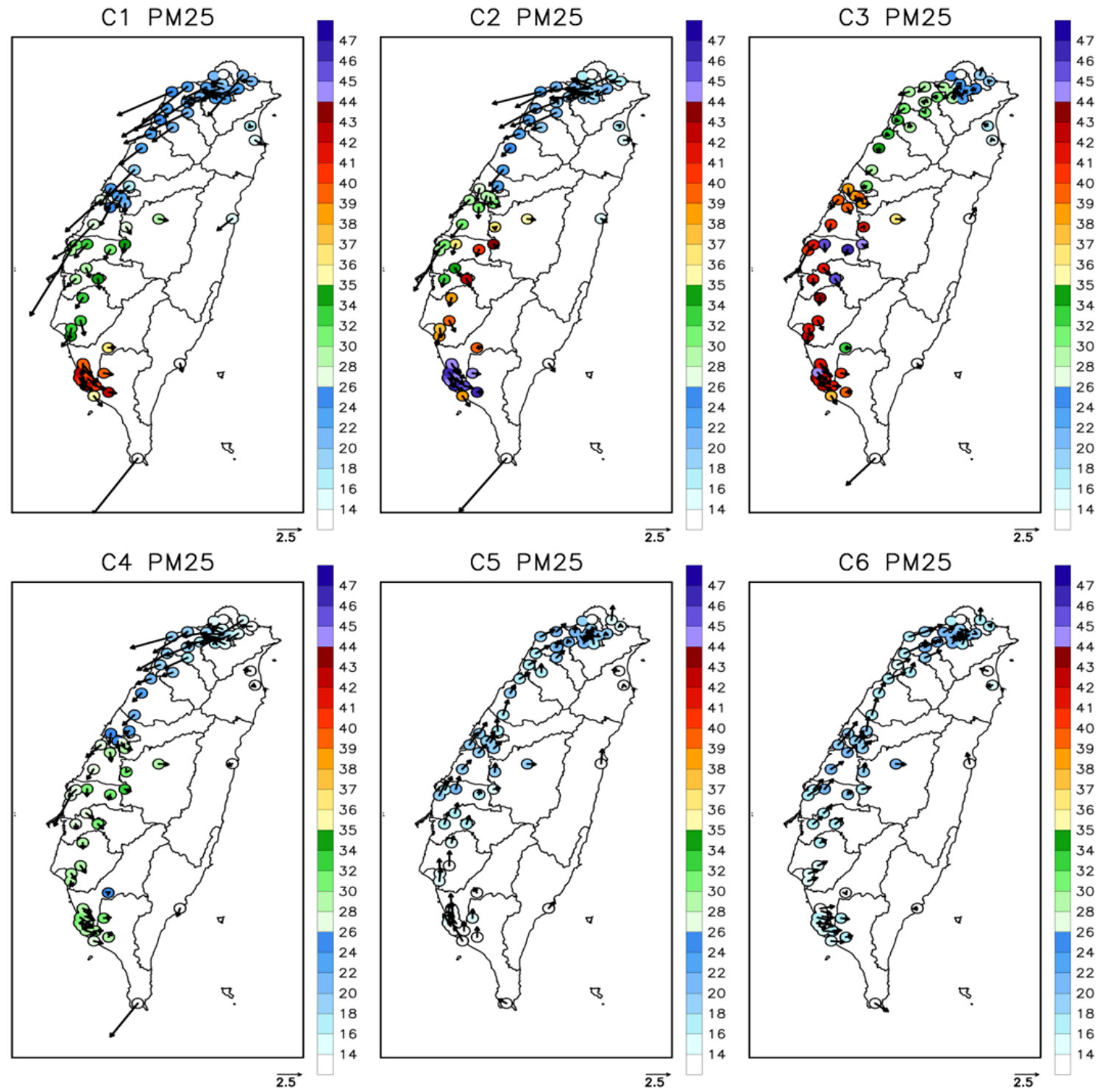

Fig. 9. Distributions of the daily mean $\mathrm{PM}_{2.5}$ concentrations $\left(\mu \mathrm{g} \mathrm{m}^{-3}\right)$ and wind vectors $\left(\mathrm{m} \mathrm{s}^{-1}\right)$ from EPA surface stations for the $\mathrm{C} 1-\mathrm{C} 6$ clusters.

for $\mathrm{C} 1-\mathrm{C} 3$. This area, as well as being under the influence of the NEM flow, is situated on the leeside of the mountains, where stagnant wind often reduces the dispersion of pollutants, and air pollutants transmitted from farther upstream further deteriorate the air quality in KP.

The results of the weather classification clearly indicate six synoptic weather patterns in Taiwan, each of which exhibits distinct meteorological conditions and associated air pollutant behaviors that vary according to the specific AQZ. Such insights help clarify the air pollution problem on this island.

\section{ACKNOWLEDGEMENTS}

This study was conducted under the research project entitled "Long-term analysis of the meteorological variables and implications on air pollutants concentrations in Taiwan" supported by the Taiwan EPA grant (EPA-107-
FALL-03-A140). The content is solely the responsibility of the grantee and does not necessarily represent the official views of the Taiwan EPA. We thank the CWB and EPA in Taiwan for providing the surface station datasets.

\section{SUPPLEMENTARY MATERIALS}

Supplementary data associated with this article can be found in the online version at http://www.aaqr.org.

\section{REFERENCES}

Cai, Z., Jiang, F., Chen, J., Jiang, Z. and Wang, X. (2018). Weather condition dominates regional $\mathrm{PM}_{2.5}$ pollutions in the Eastern Coastal Provinces of China during winter. Aerosol Air Qual. Res. 18: 969-980.

Calvo, A.I., Olmo, F.J., Lyamani, H., Alados-Arboledas, L., Castro, A., Fernández-Raga, M. and Fraile, R. 
(2010). Chemical composition of wet precipitation at the background EMEP station in Víznar (Granada, Spain) (2002-2006). Atmos. Res. 96: 408-420.

Cheng, F.Y., Chin, S.C. and Liu, T.H. (2012). The role of boundary layer schemes in meteorological and air quality simulations of the Taiwan area. Atmos. Environ. 54: 714-727.

Cheng, F.Y., Yang, Z.M., Ou-Yang, C.F. and Ngan, F. (2013). A numerical study of the dependence of longrange transport of $\mathrm{CO}$ to a mountain station in Taiwan on synoptic weather patterns during the Southeast Asia biomass-burning season. Atmos. Environ. 78: 277-290.

Chuang, M.T., Chou, C.C.K., Lin, N.H., Takami, A., Hsiao, T.C., Lin, T.H., Fu, J.S., Pani, S.K., Lu, Y.R. and Yang, T.Y. (2017). A simulation study on $\mathrm{PM}_{2.5}$ sources and meteorological characteristics at the northern tip of Taiwan in the early stage of the Asian haze period. Aerosol Air Qual. Res. 17: 3166-3178.

Coleman, J.S.M. and Rogers, J.C. (2007). A synoptic climatology of the central United States and associations with Pacific teleconnection pattern frequency. $J$. Climate 20: 3485-3497.

Fang, S.H. and Chen, H.W. (1996). Air quality and pollution control in Taiwan. Atmos. Environ. 30: 735741.

Hersbach, H. and Dee, D. (2016). ERA5 reanalysis is in production. ECMWF Newsletter 147: 7.

Hsu, C.H. and Cheng, F.Y. (2016). Classification of weather patterns to study the influence of meteorological characteristics on $\mathrm{PM}_{2.5}$ concentrations in Yunlin County, Taiwan. Atmos. Environ. 144: 397-408.

Kidson, J.W. (2000). An analysis of New Zealand synoptic types and their use in defining weather regimes. Int. J. Climatol. 20: 299-316.

Kuo, C.Y., Lin, C.Y., Huang, L.M., Wang, S., Shieh, P.F., Lin, Y.R. and Wang, J.Y. (2010). Spatial variations of the aerosols in river-dust episodes in central Taiwan. $J$. Hazard. Mater. 179: 1022-1030.

Lai, L.W. (2014). Relationship between fine particulate matter events with respect to synoptic weather patterns and the implications for circulatory and respiratory disease in Taipei, Taiwan. Int. J. Environ. Health Res. 24: 528-545.

Lin, C.Y. and Lin, C.Y. (2012). Factors affecting Aeolian dust emissions in the downstream of Zhuo-shui River. $J$. Chin. Soil Water Conserv. 43: 323-331.

MacQueen, J.B. (1967). Some Methods for Classification and Analysis of Multivariate Observations, Proc. $5^{\text {th }}$ Berkeley Symp. Math. Stat. Probability, University of California Press, Berkeley, CA, pp. 281-297.
Ngan, F. and Byun, D. (2011). Classification of weather patterns and associated trajectories of high-ozone episodes in the Houston-Galveston-Brazoria area during the 2005/06 TexAQS-II. J. Appl. Meteorol. Climatol. 50: 485-499.

Rainham, D.G.C., Smoyer-Tomic, K.E., Sheridan, S.C. and Burnett, R.T. (2005). Synoptic weather patterns and modification of the association between air pollution and human mortality. Int. J. Environ. Health Res. 15: 347-360.

Rousseeuw, P.J. (1987). Silhouettes: A graphical aid to the interpretation and validation of cluster analysis. $J$. Comput. Appl. Math. 20: 53-65.

Russo, A.C., Gouveia, C.L.M., Trigo, R.M., Liberato, M.L.R. and DaCamara, C.C. (2015). The influence of circulation weather patterns at different spatial scales on drought variability in the Iberian Peninsula. Front. Environ. Sci. 3: 42-56.

Stein, A.F., Draxler, R.R., Rolph, G.D., Stunder, B.J.B., Cohen, M.D. and Ngan, F. (2015). NOAA's HYSPLIT atmospheric transport and dispersion modeling system. Bull. Am. Meteorol. Soc. 96: 2059-2077.

TEDS-9.0 (2016). Taiwan Emission Data System Version 9.0, Environmental Protection Administration, Taipei, Taiwan, Republic of China.

Tsai, D.H., Wang, J.L., M., Wang, C.H. and Chan, C.C. (2008). A study of ground-level ozone pollution, ozone precursors and subtropical meteorological conditions in central Taiwan. J. Environ. Monit. 10: 109-118.

Tsai, H.H., Ti, T.H., Yuan, C.S., Hung, C.H. and Lin, C. (2008). Effects of sea-land breezes on the spatial and temporal distribution of gaseous air pollutants at the coastal region of southern Taiwan. J. Environ. Eng. Manage. 18: 387-396.

Tsai, H.H., Yuan, C.S., Hung, C.H. and Lin, C. (2011). Physicochemical properties of $\mathrm{PM}_{2.5}$ and $\mathrm{PM}_{2.5-10}$ at inland and offshore sites over southeastern coastal region of Taiwan Strait. Aerosol Air Qual. Res. 11: 664678.

Vanos, J.K., Cakmak, S., Kalkstein, L.S. and Yagouti, A. (2015). Association of weather and air pollution interactions on daily mortality in 12 Canadian cities. Air Qual. Atmos. Health 8: 307-320.

Yen, M.C. and Chen, T.C. (2000). Seasonal variation of the rainfall over Taiwan. Int. J. Climatol. 20: 803-809.

Received for review, September 17, 2018 Revised, December 16, 2018 Accepted, February 3, 2019 